\title{
Os Sentidos da Ação Estatal nos Anos 1930: Centralização Política e Intervencionismo na Constituição de 1934
}

\section{The Senses of State Action in the Years 1930: Political Centralization and Interventionism in the 1934's Constitution}

\author{
Jorge Armindo Aguiar Varaschin ${ }^{a}$
}

\begin{abstract}
Resumo: O presente trabalho apresenta-se como um esforço de interpretação do novo sentido da ação estatal institucionalizado na Constituição de 1934, primeira carta constitucional elaborada no pós-Revolução de 1930, período em que se desmancha o bloco de poder hegemônico durante a Primeira República. Dessa forma, através da análise das contradições específicas do momento histórico, busca-se compreender as descontinuidades apresentadas pela nova conjuntura, na medida em que a forma assumida pelo Estado nacional estabelece um processo de centralização política e de construção de instrumentos jurídico-institucionais para o intervencionismo econômico, marcando uma nítida diferença em relação ao liberalismo da Constituição de 1891.
\end{abstract}

Palavras-chave: Economia brasileira. Liberalismo. Intervencionismo. Estado nacional.

Abstract: This paper presents itself as an effort to interpret the new direction of the state action institutionalized by the 1934 Constitution, the first one to be developed after the "Revolution" of 1930, a time in which the power bloc that was hegemonic during the First Republic is dismantled. Through the analysis of the specific contradictions of this historic moment, it looks to comprehend the discontinuities presented by the new scenario, as the configuration assumed by the National Government to establish a process of political centralization and the construction of judicial and institutional instruments for economic intervention sets a clear difference to the liberalism of the 1891 Constitution.

Keywords: Brazilian economy. Liberalism. Economic intervention. National government.

JEL Classification: N16; N46.

\section{Introdução}

A década de 1930 marca um novo período na história do Brasil republicano. As alterações ocorridas no arranjo político existente durante a Primeira República, bem como o início do processo de industrialização nacional constroem uma nova etapa na formação do capitalismo brasileiro, como demonstrado por Celso

Universidade Federal do Rio Grande do Sul (UFRGS), Faculdade de Ciências Econômicas, Programa de Pós-graduação em Economia. Porto Alegre, Rio Grande do Sul, Brasil. 
Furtado (1997) em Formação Econômica do Brasil. Nesse sentido, apresenta significativas descontinuidades políticas e econômicas já que a mudança no bloco de poder hegemônico representa a perda da primazia do capital cafeeiro e, consequentemente, uma reconfiguração na dinâmica de classes. Consideram-se os impasses político-econômicos criados no decorrer da década de 1920 como aspectos centrais nas alterações no processo de acumulação de capital, significando as transformações testemunhadas nos anos seguintes. A Revolução de 1930 surge, nesse contexto, como o que se poderia chamar de uma resolução específica, um desfecho das contradições em desenvolvimento intrinsecamente ligadas à singularidade do momento histórico sob o qual lança suas bases. Em outras palavras, a centralização política e o intervencionismo surgem como respostas, em 1930, para os impasses herdados do período anterior. Portanto, a Constituição de 1934 aparece como um dos primeiros elementos jurídico-institucionais do novo contexto econômico, político e ideológico. É justamente a maneira como ela herda e reflete o momento do qual faz parte o objetivo deste trabalho, seu objeto de análise.

Compreende-se que a ampliação da acumulação durante a década de 1920 e os problemas apresentados para sua realização, estabelecendo as bases para crises de superprodução, tornam o movimento do capital cafeeiro cada vez mais dependente da política de manutenção dos preços iniciada nos anos de 1900. Contudo, à medida que as contradições se aprofundam, tal dependência entra em choque com a estreita base tributária que compõe a estrutura de financiamento estatal no período, basicamente taxação sobre importações, o que leva, ano após ano, à elevação da dívida externa brasileira para fazer frente à política valorizadora. Chega-se, assim, a um cenário tanto de crise do modelo primário-exportador quantode esgotamento do modelo de política econômica que o sustenta, através das repetidas operações de sustentação de preços do café.

Em sua face político-ideológica, o desenvolvimento das condições descritas traz a deterioração progressiva do bloco de poder dominante durante a Primeira República, tendo em vista que o capital cafeeiro já não consegue justificar sua dominância de classe, elemento essencial para a construção de qualquer hegemonia. Com isso, abre-se espaço para contestações de outras frações da burguesia agrária nacional, tanto no que diz respeito à condução da economia quanto aos pilares político-ideológicos da dominação do café. De maneira geral, ambas as críticas eram expostas de modo conjunto e articulado. O liberalismo observado na Constituição de 1891, base que legitima a forma de Estado então existente e constrói o elemento ideológico da hegemonia do capital cafeeiro, sofre graves contestações com o aumento da dependência das intervenções no mercado de café. Como base na qual se assenta esse discurso, a solidez fiscal e o não intervencionismo estatal são seriamente ameaçados pelo prosseguimento das operações valorizadoras. As contradições entre as condições para a acumulação e o aparato 
institucional existente na época aparecem no nível ideológico como contestações à própria forma do Estado constituído. A chamada cisão oligárquica, nesse sentido, conduz às críticas não apenas das contradições específicas ligadas ao equilíbrio orçamentário e à intervenção estatal na economia, mas a todo corpo ideológico que embasa a Constituição de 1891. Em síntese, a crítica surge não somente à dominância do café, mas também à forma de Estado que o instrumentaliza e ao liberalismo que o legitima. Nesse sentido, condena-se o poder exagerado por parte dos estados, a descentralização administrativa e a ausência de mecanismos institucionais para a intervenção estatal na economia. Essa problemática surge sob os contornos da Aliança Liberal, em seguida no movimento armado de 1930 e aparecerá pela primeira vez formalizada em instrumentos jurídico-institucionais na Constituição de 1934, apresentando os primeiros elementos para a elaboração do projeto desenvolvimentista.

Para a investigação desse processo, o trabalho se divide em mais quatro seções, além desta introdução: a segunda trata do modo como as contradições da acumulação cafeeira, aprofundadas na década de 1920, corroem a dominação do capital cafeeiro, abrindo espaço para que outras frações da burguesia agrária nacional contraponham-se à dominância de classe estabelecida, mediante crítica da condução da economia e da forma de Estado constituída pelo liberalismo da Constituição de 1891; a terceira analisa os primeiros elementos de uma nova forma de Estado surgida com o fim da Primeira República através do surgimento de um projeto nacional calcado no movimento de industrialização e como este elabora um novo sentido para a ação estatal; a quarta discute os primeiros instrumentos jurídico-institucionais que a operacionalizam, dando ênfase à Constituição elaborada em 1934, primeira sistematização jurídica surgida no pós-1930. Por fim, a quinta traça as considerações finais da análise.

\section{Acumulação Cafeeira, Bloco de Poder e Liberalismo: Dinâmica e Contradição}

A década de 1920 trouxe uma nova fase expansiva do ciclo do setor exportador, considerado por Mello (1982) como o segundo ciclo longo do café. De acordo com o autor, a produção média do produto passou de 14,1 milhões de sacas, no fim da década de 1910, para 18,2 milhões, entre os anos de 1924-1925 e 19281929, alcançando o montante de 24,2 milhões de sacas em 1930. Os preços do produto, após o boom resultante da retomada do comércio internacional em decorrência do término da Primeira Guerra Mundial, sofreram uma queda acentuada, determinando uma diminuição no poder de compra das exportações. Já a redução da atividade econômica dos países centrais, consequência da adoção de 
políticas restritivas, visava a redução da pressão inflacionária. A queda acentuada da taxa de câmbio, decorrente da

[...] aceleração tardia do volume de importações estimulada pelo boom e pela apreciação cambial anteriores, provocando súbita reversão da balança comercial em meados de 1920, o que, além de ter efeito fortemente recessivo, causaria grande depreciação cambial a partir do segundo semestre desse ano (FRITSCH, 1992, p. 46).

levou à deterioração da solidez fiscal do estado, o que gerou elevados déficits governamentais, balanceados com uma forte contração dos gastos do governo. Além disso, a falta de um emprestador de última instância reduz a flexibilidade da política monetária, obrigando os bancos a operarem com quase 50\% de reservas em moeda corrente (VILLELA; SUZIGAN, 1973). Nessa conjuntura, aliada à forte safra de 1921-1922 e à crise da economia norte-americana, ocorre a chamada terceira valorização:

Recolheram-se 4.500.000 sacas, mediante empréstimo tomado à Carteira de Redesconto do Banco do Brasil, depois consolidado, justamente a outros empréstimos menores, mediante o Empréstimo de Garantia do Café, concedido pelo Rotschild, por Schoroeder e Baring Brothers, em 1922 (MELLO, 1982, p. 159).

Ainda segundo o autor, a operação de valorização conseguiu deter a baixa do preço da saca de café, bem como obteve uma leve recuperação em 1922 e 1923. A partir daí, a política de valorização do produto passou a ter caráter permanente, conduzida, até 1924, pelo governo federal, ano em que a operação tornou-se responsabilidade do governo do estado de São Paulo. Para tanto, criou-se o Instituto do Café, órgão responsável pelo controle do produto no país e pelos empréstimos sob o café retido. Em 1927, o instituto estabeleceu cotas mensais de oferta do café, sendo que o excedente era retido através de empréstimo do Banco do Estado de São Paulo. No entanto, a forte safra de 1927-1928 obrigou a busca de financiamento junto ao Lazard Brothers, no que ficou conhecida como "Valorização de Rolim Teles" (MELLO, 1982, p. 161).

Já nesse período, revela-se a incompatibilidade entre a política de valorização, em seu caráter permanente, e a estreita base tributária do Estado brasileiro, incapaz de, por si só, fazer frente ao montante necessário pela política valorizadora. Nessa época, a necessidade de financiamento compunha-se tanto das operações de valorização quanto dos investimentos estatais, importante elemento dentro do investimento nacional, o que dificultava ainda mais a conjuntura fiscal. Em síntese, a dinâmica econômica da década de 1920 demonstra que a manutenção da hegemonia do capital cafeeiro agravava progressivamente o cenário de dependência externa, fazendo com que o descompasso entre a dependência comercial e financeira apresentasse como contrapartida a elevação da dívida externa. Nesse 
contexto, a taxa de câmbio tornava-se elemento central de ajuste, além da necessidade cada vez maior de elevação da taxação das importações ou, nas palavras de Alvarenga Júnior e Mattos (2015, p. 21): "Tratava-se, portanto, de buscar uma forma de conciliar a defesa dos lucros do setor exportador [...] e a valorização cambial, necessária à saúde das contas públicas e ao poder de compra da coletividade, mas, acima de tudo, imposta pelos credores externos". Silva (1976) expõe o impasse da seguinte maneira:

Durante um certo tempo, a grande burguesia cafeeira enfrenta esse "de-
sequilíbrio externo" através da desvalorização constante da moeda bra-
sileira. Essa política entretanto agrava ainda mais o problema da dívida
externa, de modo que, em 1898, é necessário apelar para uma operação
de funding-loan. Para pagar o funding-loan, o governo federal é obrigado
a adotar uma política de austeridade financeira, diminuir as suas despe-
sas e aumentar as suas receitas, isto é, aumentar os impostos. Ora, as ex-
portações não podem ser taxadas pelo governo sem colocar em questão
o equilíbrio político das próprias classes dominantes e, em particular, a
posição hegemônica da grande burguesia cafeeira. [...] Assim, em ra-
zão da lógica da acumulação determinada pela posição subordinada da
economia brasileira no seio da economia mundial, o governo é levado a
aumentar as taxas sobre as importações. (SILVA, 1976, p. 105).

A transferência da responsabilidade das operações valorizadoras evidencia o esgotamento da capacidade do Estado nacional para prosseguir com a política de manutenção de preços do café sem colocar em risco as bases de sua estrutura tributária. Contudo, demonstrando o agravamento das contradições de acumulação, mesmo quando as operações passam para o controle do governo do estado de São Paulo, o impasse se mantém. A necessidade cada vez maior de recursos para operações mais dispendiosas, ano após ano, apresenta os contornos daquilo que se pode chamar de uma crise de superprodução permanente (ver a Tabela 1). É nesse sentido que a ampliação do capital cafeeiro entra em choque com a solidez fiscal, seja do governo federal, seja do governo do estado de São Paulo. 
Tabela 1 - Balança comercial e dívida externa no Brasil (1920-1930)

\begin{tabular}{c|c|c|c}
\hline \multirow{2}{*}{ Anos } & \multirow{2}{*}{$\begin{array}{c}\text { Saldo da balança } \\
\text { comercial (1.000 libras) }\end{array}$} & \multicolumn{2}{|c}{ Dívida externa (1.000 libras) } \\
\cline { 3 - 4 } & & $\begin{array}{c}\text { Novos } \\
\text { empréstimos }\end{array}$ & Pagamento \\
\hline 1920 & -6.023 & - & 10.065 \\
1921 & -622 & 20.336 & 10.781 \\
1922 & 17.708 & 17.717 & 11.297 \\
1923 & 21.151 & - & 11.027 \\
1924 & 24.235 & - & 10.278 \\
1925 & 18.432 & 3.082 & 10.252 \\
1926 & 14.378 & 29.246 & 15.078 \\
1927 & 9.055 & 26.622 & 15.955 \\
1928 & 6.757 & 25.293 & 18.696 \\
1929 & 8.178 & 2.877 & 19.175 \\
1930 & 12.127 & 20.000 & 21.642 \\
\hline
\end{tabular}

Fonte: Villela e Suzigan (1973, p. 451).

Esse dilema, do ponto de vista dos obstáculos ao prosseguimento do capital cafeeiro, aparece na dinâmica político-ideológica como a progressiva deterioração do bloco de poder hegemônico durante a Primeira República, capitaneado pelo café através, principalmente, da figura do cafeicultor paulista. O liberalismo reinante na Constituição de 1891 molda a forma de Estado que operacionaliza sua predominância. A falta de instrumentos para a intervenção estatal na economia, a descentralização administrativa e a elevada autonomia dos estados, fruto do federalismo existente, constroem uma estrutura estatal que possibilita a hegemonia do café: pela renda e receitas geradas, prossegue como produto principal da economia nacional. Para além da solidez fiscal, elemento do discurso liberal que aparece associado a não intervenção estatal, a dinâmica política do período instrumentaliza o federalismo da carta constitucional. Em síntese, o pacto de Campos Sales e a consequente política dos governadores, dando vazão à autonomia dos estados, inauguram um período em que a esfera estadual se apresenta como palco legítimo para a formação dos atores políticos em nível nacional (BACKES, 2004). Desse modo, na arena política, os interesses em jogo se obscurecem: o capital cafeeiro aparece, numa estrutura regionalizada, como perspectiva dos "paulistas", assim como as outras frações da burguesia agrária nacional regionalizam-se em seus estados, consolidando, desse modo, oligarquias estaduais, através, geralmente, de seus respectivos partidos republicanos (FONSECA, 1999). Constrói-se, com isso, no nível político-ideológico, um sujeito regionalizado: o "nós" apresentado não se constitui como cafeicultores ou capitalistas, oligarcas ou fazendeiros, mas se 
fará de outro modo: "nós" como paulistas, gaúchos ou mineiros. E o "outro", parte constituinte de qualquer discurso, se apresentará da mesma maneira. Desse modo, já se pode adiantar a principal descontinuidade ideológica do período pós1930: a chegada de Getúlio Vargas ao poder, possibilitada pela Revolução de 1930, inaugura o período de formação de um novo sujeito, base para a constituição dos discursos que a partir daí virão, qual seja, o sujeito nacional: "nós" como brasileiros. A concretização desse discurso dar-se-á mediante o fortalecimento do poder central em detrimento das esferas estaduais e pela construção de novas relações jurídico-institucionais capazes de dar suporte ao projeto implícito nesse sujeito. Esse processo, portanto, marca a gênese do Estado desenvolvimentista brasileiro, tendo em vista que representa a instrumentalização de determinada "visão de mundo". É o discurso desenvolvimentista, junto às transformações econômicas e políticas verificadas no país a partir de 1930, que cria a realidade na qual essa nova estrutura estatal possui um sentido.

Nesse contexto, o não intervencionismo econômico e o federalismo institucionalizado em 1891, somados à defesa da solidez fiscal, tão necessária para a obtenção de crédito externo, e às operações do capital financeiro, aparecem como os elementos mais importantes para o liberalismo brasileiro durante a Primeira República. Entende-se porque o aprofundamento das operações valorizadoras surge como fator que desestabiliza não apenas a dinâmica econômica dos anos 1920, mas também, e consequentemente, as bases político-ideológicas que a mantinham. As contradições entre as condições de acumulação e a ideologia e o corpo institucional que a possibilita e legitima cria progressivamente o espaço para contestações de outras frações da burguesia agrária nacional. Enquanto a renda e as receitas provenientes do café continuam em movimento ascendente, as contestações são dirimidas e absorvidas pelo discurso dominante. Entretanto, à medida que a dependência entre capital cafeeiro e política valorizadora se aprofunda, as contestações encontram espaços para se articular:

Ficava claro [...] que o pacto político que assegurava a hegemonia das oligarquias mais importantes começava a balançar na década de 1920. O intervencionismo para garantir os preços do café no mercado internacional aprofundava-se e executava-se cada vez com maior freqüência. A convicção de que o café sustentava o Brasil transformava-se em seu oposto: a economia cafeicultora "socializava os prejuízos", era a voz corrente [...] (FONSECA, 1999, p. 119).

Com relação ao movimento do capital nacional, a síntese produzida pela superação das contradições inerentes à acumulação cafeeira se apresenta da seguinte forma: a base fiscal e monetária da acumulação levará, invariavelmente, ao aumento da produção industrial (ver Tabela 2). O papel protecionista desempenhado tanto pela desvalorização cambial quanto pelo aumento da taxação das im- 
portações, concomitantemente ao aumento da dívida externa e/ou à deterioração progressiva do setor cafeeiro, possibilita esse movimento. Compreende-se porque Mello (1982) afirma que a década de 1920 trouxe, além dos problemas referidos, a elevação e a diversificação do setor industrial.

Tabela 2 - Índices do volume físico da produção por setores no Brasil (19201930): base $1939=100,0$

\begin{tabular}{c|c|c|c}
\hline Ano & Agricultura & Indústria & Produto físico \\
\hline 1920 & 57,8 & 34,7 & 47,4 \\
1921 & 60,5 & 34,3 & 49,0 \\
1922 & 60,3 & 39,7 & 50,5 \\
1923 & 61,4 & 47,4 & 53,3 \\
1924 & 63,5 & 39,6 & 52,9 \\
1925 & 61,5 & 39,9 & 51,7 \\
1926 & 63,7 & 39,5 & 53,1 \\
1927 & 69,2 & 42,7 & 57,6 \\
1928 & 82,1 & 46,1 & 67,0 \\
1929 & 82,1 & 44,5 & 66,9 \\
1930 & 82,9 & 42,4 & 66,4 \\
1931 & 77,9 & 45,9 & 64,4 \\
1932 & 83,3 & 46,0 & 67,9 \\
1933 & 90,7 & 52,8 & 74,9 \\
1934 & 94,8 & 59,6 & 80,0 \\
1935 & 91,3 & 68,0 & 81,4 \\
1936 & 99,8 & 77,8 & 90,4 \\
1937 & 99,7 & 83,3 & 92,5 \\
1938 & 103,4 & 88,8 & 96,9 \\
1939 & 100,0 & 100.0 & 100,0 \\
\hline
\end{tabular}

Fonte: Villela e Suzigan (1973, p. 431).

Em 1926, com a posse de Washington Luís, há a tentativa de volta ao padrão-ouro com a criação da Caixa de Estabilização, o que, em um contexto de retomada do comércio exterior, resulta em uma expansão monetária e, consequentemente, em uma desvalorização cambial. A valorização do café operada pelo governo do estado de São Paulo, após a obtenção de um novo empréstimo por parte do Banco do Estado, impacta positivamente no preço do produto. Segundo Fritsch (1992, p. 58), "A grande onda de investimentos estrangeiros reiniciada em 1926 mais do que compensou a redução do saldo em conta corrente, e o elevado superávit no balanço de pagamentos induziu rápida expansão das emissões da Caixa 
até meados em 1928". Já agora se apresentam as condições de êxito para a manutenção de tal estrutura, qual seja, a existência de um cenário externo favorável.

Em 1928, todavia, o cenário se altera. Problemas na balança comercial, juntamente com a diminuição no fluxo de capitais externos, levaram à adoção de políticas de crédito restritivas. Nas palavras de Fritsch (1992, p. 60), "[...] a estagnação das exportações num contexto de crescimento acelerado das importações, induzido pela recuperação dos níveis de atividade e investimentos domésticos [...]" acarreta uma deterioração do saldo comercial, diminuindo as emissões da Caixa de Estabilização, criando um cenário deflacionista.

Com a safra recorde de 1928-1929, elevam-se as pressões sobre o Instituto do Café, que, nesse momento, buscava um empréstimo externo para a manutenção da política valorizadora. No entanto, "[...] foi a progressiva deterioração das condições de crédito em Londres no terceiro trimestre de 1929, que bloqueou definitivamente a alternativa de obtenção de financiamento externo pelo Instituto no futuro previsível [...]" (FRITSCH, 1992, p. 61).

Dessa forma, exacerbam-se as contradições inerentes à dinâmica de acumulação. A progressiva deterioração do cenário externo acarreta problemas nas transações correntes, bem como no fluxo de entrada de capitais externos, minando as condições necessárias para o prosseguimento da acumulação cafeeira. No mesmo período, a face política da crise aparece com o aprofundamento das críticas ao bloco de poder dominante, fazendo da década de 1920 um momento rico "[...] em movimentos políticos de contestação ao situacionismo, com inúmeros fatos sintomáticos da crise da hegemonia cafeicultora paulista [...]" (FONSECA, 1999, p. 119). Na dinâmica política, o situacionismo abre um período de concessões, tendo como resultado a aprovação, na Câmara dos Deputados, de "[...] várias emendas com o objetivo de transformar a defesa do café em defesa permanente da produção nacional, abrangendo a borracha, o cacau, o algodão, o fumo, o açúcar, o mate, obedecidas as especificidades de cada produto [...]" (FAUSTO, 1975, p. 237).

Uma questão importante que surge nessa conjuntura é a seguinte: por que o liberalismo não ajuda a resolver ideologicamente as incongruências entre a dinâmica econômica e o jogo político do período, tendo em vista ser a base ideológica da hegemonia do pacto de poder em cuja centralidade encontram-se os cafeicultores paulistas? A questão surge em meio ao debate sobre a história econômica brasileira: a política econômica da Primeira República foi, de fato, benéfica ao setor cafeeiro? Nesse ponto, fica nítido porque "a política econômica do Pacto" torna-se "mais do que simples defesa do café" (BACKES, 2004, p. 169). Entende-se que a legitimidade ideológica do período sustenta-se na medida em que a política econômica não se choca com as articulações constituintes do discurso liberal, tendo em vista sua relevância basilar para a manutenção do bloco de poder. Nessa 
medida, dada a conjuntura econômica, política e ideológica do final da década de 1890, quando se formam as articulações características do liberalismo brasileiro, estas se apresentam como as bases possíveis para a constituição do bloco de poder hegemônico, o que não significa, necessariamente, as melhores articulações para a defesa dos interesses específicos da cafeicultura paulista. Apesar disso, o que se pretende explicitar é que a defesa do orçamento equilibrado apresenta-se como a defesa ideológica do bloco de poder dominante, em cujo centro, como referido anteriormente, se encontram os cafeicultores paulistas. Nesse contexto, há uma mudança no sujeito ideológico constituído: a defesa da austeridade fiscal relaciona-se, historicamente, aos cafeicultores, tendo em vista sua centralidade na dominação ideológica, no entanto, não como tais, mas como liberais. Assim, a polêmica referida e que tanto debate causou na literatura econômica se dissipa. Esquece-se frequentemente que, além de cafeicultores, paulistas e fazendeiros, apresentavam-se, em sua grande maioria, como liberais. Dessa forma, constrói-se o consenso, não em torno dos interesses declarados da cafeicultura ou dos paulistas, porém ao redor dos já citados princípios liberais. A dominação de classe se desvanece: restam apenas sujeitos ideologicamente constituídos que formam sua realidade na crença de sua plena autonomia individual.

Uma amostra disso é o fato de que, nos momentos em que se mostrava inconsistente a solidez fiscal com o prosseguimento da política de valorização, optava-se pela primeira. Já em 1924, Arthur Bernardes, frente à incapacidade de o governo federal continuar capitaneando a política de valorização do café, não hesitou em passar para as mãos do governo do estado de São Paulo a responsabilidade de sua realização. Já em 1929, com o estouro da crise econômica global, Washington Luís institui o "salve-se quem puder" (AURELIANO, 1981, p. 80), afirmando que "[...] a defesa do café não lhe interessava mais, recorrendo ao exemplo da Inglaterra, que abandonara a borracha." (AURELIANO, 1981, p. 79).

Ironicamente (ou não), quem procede à defesa da renda do capital cafeeiro é Getúlio Vargas a partir de 1930. Antes disso, a perda de hegemonia da burguesia agrária paulista, juntamente com a crise do capital cafeeiro, leva à chamada cisão oligárquica, culminando na formação da Aliança Liberal e, posteriormente, na Revolução de 1930.

\section{Revolução de 1930 e Governo Provisório: Sujeito Nacional e Elementos do Discurso Desenvolvimentista}

Passa-se agora a análise dos elementos formadores da Aliança Liberal e do Governo Provisório, momentos que serão cristalizados em 1934 com a promulgação da nova carta constitucional, destacando aspectos novos e suas principais descontinuidades com o período anterior. 


\subsection{A Aliança Liberal}

Segundo Fonseca (1989, p. 140), "A formação da Aliança Liberal demonstra seu caráter oligárquico, mesmo porque gestada dentro das estruturas políticas, econômicas e institucionais da República Velha, o que não impede que seja revelada sua outra face, àquela vinculada: a burguesa." Nesse sentido, a chapa aliancista representa a tentativa das oligarquias de outros estados de ganhar terreno na crise do bloco de poder então dominante. Como afirmado anteriormente, dentro do jogo político-ideológico da época, a disputa aparecia como embate entre estados, dado o sujeito regional constituído a partir de 1898 e que caracterizava a Primeira República, evidenciando o papel assumido pelo Partido Republicano de cada estado, na medida em que congregavam as oligarquias estaduais. Dessa forma, a plataforma da Aliança Liberal expressa essa configuração política, com elementos que refletem os interesses de diferentes setores:

Tratava-se, portanto, de um programa burguês em toda a acepção da palavra, seja com relação ao capital, procurando acomodar suas diversas frações dentro de determinada circunstância histórica e com base em certa correlação de forças políticas, seja com relação ao trabalho, buscando sua adaptação e submissão ao capital. Os políticos das oligarquias dissidentes expressavam os interesses das classes dominantes de seus estados; e, nestes o peso, do setor primário na economia era maior que em São Paulo, a Plataforma deixava isso transparecer. Não se tratava de excluir a burguesia industrial, mesmo porque esta nos estados aliancistas apoiou a chapa Vargas-João Pessoa, da mesma forma que as principais associações industriais de São Paulo lançaram manifesto em favor de Júlio Prestes. O PRR era por excelência o partido dos industriais gaúchos, da mesma forma que o PRP o era dos paulistas. Os industriais não foram excluídos da Aliança Liberal pela mesma razão que não o foram da chapa oficial: faziam parte, na República Velha, dos partidos situacionistas estaduais (FONSECA, 1989, p. 127).

Com relação à plataforma, expressa a variedade política na base da Aliança, compondo-se de demandas regionais e apelos específicos de certos setores (exército, por exemplo), além de tratar de temas de "interesse geral", como educação e saúde (FONSECA, 1987, p. 21). Nesse sentido, apesar da existência de elementos que propunham determinadas descontinuidades, como a proposta de regulamentação das leis trabalhistas, nota-se uma forte dose de continuidade. Com relação ao dilema anteriormente citado, entre discurso liberal e acumulação cafeeira, reproblematiza o segundo, tendo em vista uma nova proposta na defesa do café, vinculada agora à redução de custos, e não mais à sustentação de preços. Enfim, a própria caracterização da Aliança Liberal sugere um caminho, qual seja, liberal. Apresentava-se, assim, como uma união entre liberais. Na construção do consen- 
so, aparece o sujeito comum. Apesar da diversidade anteriormente citada, grande parte identificava-se com o liberalismo.

\subsection{Governo Provisório}

O governo provisório iniciou com a vitória do golpe liderado por Vargas em 1930. A chamada Revolução de 1930 liquida com o arranjo político representado pela Primeira República e desmonta as principais bases do bloco de poder hegemônico no pré-1930. Inicia-se, assim, um novo pacto político-ideológico no país. A análise econômica foi feita no capítulo anterior e constata o desencadear do movimento de industrialização nacional. Do ponto de vista político-ideológico, o período representa o início da construção de um novo discurso, baseado em um novo sujeito interpelado. Este se concretiza em um novo tipo de Estado, caracterizado por uma mudança na relação com a sociedade civil. Constitui-se o início da formação do discurso desenvolvimentista, cuja interpelação central aparece como um sujeito nacional: "nós" como brasileiros. Tal, no nível concreto, legitima o processo de centralização estatal, perda do poder dos estados e intervencionismo econômico. Além disso, dará novo sentido à ação estatal, visto que constituirá um projeto nacional. Assim, apresenta um ponto de partida e outro de chegada e, entre eles, um caminho: o discurso desenvolvimentista amalgamará ideologicamente os três. Forma-se, nesses termos, a realidade do chamado Brasil moderno (FERNANDES, 1968).

Tem-se, assim, a principal descontinuidade político-ideológica em relação ao período anterior: o discurso desenvolvimentista gesta-se na crise e deterioração do bloco de poder dominante, cuja realidade construiu-se a partir do relato liberal. Desse modo, seus elementos constituem-se sob uma visão crítica à realidade precedente, apresentando suas articulações como superações do discurso anterior, visto como atrasado e em descompasso com as necessidades nacionais. Dessa forma, emerge como primeira característica seu antiliberalismo, o que torna seus elementos constituintes uma contraposição àqueles do pré-1930. Isso fica nítido, por exemplo, com a construção do sujeito nacional, já que este supera os conflitos entre estados: se o primeiro possuía como aspecto central um sujeito regionalizado e tinha como elemento simbólico essencial a defesa do orçamento equilibrado, o segundo articula um sujeito nacional e a necessidade de seu desenvolvimento. Apesar disso, a austeridade fiscal sempre aparecerá nos discursos de Vargas. No entanto, perde terreno e a centralidade que possuía na década anterior: ocupa, agora, posição subordinada à necessidade de desenvolvimento da nação, o que, na época, significa sua industrialização. Nesse sentido, o discurso desenvolvimentista constrói um elemento pouco tratado nos anos 1920: o processo de industrialização. Essa associação marcará o desenvolvimentismo como discurso, redimen- 
sionando o papel do Estado nacional. Este, agora, encarna a vontade do desenvolvimento e a política econômica deve, necessariamente, subordinar-se a essa meta. Entende-se, assim, o sentido da "inovação" trazida com a década de 1930: o aumento do crédito, a criação de instituições para a diversificação agrícola e crescimento industrial, o aumento do investimento e do intervencionismo estatal, todos esses fatores constroem seu sentido a partir da realidade expressa e ordenada pelo discurso desenvolvimentista.

Compreende-se, nesse momento, a contribuição dada por Fonseca (2003) referente à intencionalidade da política industrializante durante a década de 1930. A ideologia desenvolvimentista, aqui em seu nascedouro, elabora as bases político-ideológicas sob as quais a criação consciente de instituições e outros órgãos servirão como alicerces do crescimento da produção industrial. A realidade, enfim, aparece como fruto de uma interpretação e a desenvolvimentista constrói o sentido daquilo que prega:

Neste sentido, pode-se demonstrar que as instituições criadas e/ou modificadas na década de 1930 pelo governo brasileiro evidenciam sua opção industrializante, pois representam mecanismos, regras, arenas e espaços para, dentro do aparelho estatal e sob sua influência, reorientar a economia, definindo nova relação estado/empresariado/mercado/trabalhador (FONSECA, 2003, p. 135).

Do ponto de vista ideológico, tal cenário constrói-se na medida em que a necessidade do desenvolvimento da nação apresenta-se como objetivo maior a ser buscado pelo governo. Em um artigo sobre o tema, o mesmo autor afirma:

Neste ideário, o desenvolvimento não é apenas uma palavra de ordem a mais, mas o elo que unifica e dá sentido a toda ação do governo, ao legitimar a ampliação de sua esfera nos mais diferentes campos [...] Assim, o desenvolvimento assume a configuração de uma utopia [...] (FONSECA, 2004, p. 227).

Os elementos que formarão esse novo ideário aparecerão já no período considerado, não esquecendo, é claro, que a década de 1930 surge como momento de gestação dessa nova ideologia. A Constituição de 1934 mostra esse cenário, como veremos mais adiante.

\subsubsection{Centralização Política e Intervencionismo Estatal}

Dada a análise anterior, já temos elementos para tentar a reconstrução político-ideológica do período, tendo em vista os vários elementos de descontinuidade em relação ao pré-1930. A apreensão das tendências que advirão marcam a gênese de um novo tipo de Estado, baseado em um novo arranjo político-ideológico, do qual a Constituição promulgada em 1934, invariavelmente, faz parte. Assim, 
analisam-se agora as tendências políticas do momento, investigando como e em que medida transformam o aparelho estatal.

Para Draibe (1986), o novo contorno estatal estabelecido no pós-1930 surge na tentativa de "estatizar" as relações econômicas de classe, promovendo sua consequente politização. Assim, o Estado internaliza os conflitos e atua, nesse sentido, como dirigente: "[...] o Estado é dirigente. Vale dizer, coloca no limite, além dos horizontes dos interesses dominantes, um projeto de transformação capitalista da economia e da sociedade [...]" (DRAIBE, 1986, p. 44). Ainda segundo a autora, tal situação apenas se torna possível pela relativa autonomia do Estado no período, tendo em vista a grande fragmentação e heterogeneidade das forças sociais e políticas:

Assim, se a heterogeneidade e a incapacidade hegemônica das classes
sociais fundaram a autonomia do Estado, as correlações instáveis de for-
ça definidas no campo da luta política demarcavam não apenas os limites
em que se exerceria esta ação autônoma como o sentido que ela haveria
de ter (DRAIBE, 1986, p. 63).

Do mesmo modo, para Fonseca (1989, p. 184), “[...] entender o Estado pós1930 significa não apenas identificar seu conteúdo de classe, mas as novas formas que ele foi tomando, reatualizando velhas questões e procurando solucioná-las sob determinada correlação de forças políticas existentes". Dessa forma, para os dois autores, tal transformação baseou-se, principalmente, na centralização política e no intervencionismo estatal (DRAIBE, 1986; FONSECA, 1987, 1989, 2003):

A extensão e o aprofundamento do Estado do intervencionismo evidenciam-se na burocratização, racionalização e centralização da tomada de decisões, tendo como pólo impulsionador o governo federal. Estas vão facilitando mudanças - econômicas, políticas e sociais -, que se constituem verdadeiro processo de transformação capitalista (FONSECA, 1989, p. 193).

Para Draibe (1986), essa centralização se processa de duas maneiras: com a "construção de um novo arcabouço jurídico-político estatal", com o objetivo de formar uma nova base organizacional para o funcionamento do Estado; e com a "edificação de um aparelho burocrático-administrativo de intervenção, centralização e controle":

A centralização trouxe consigo elementos novos, que alteraram a qualidade e a natureza do conjunto de instrumentos políticos ou de regulação e controle anteriormente vigentes. Velhos órgãos ganharam nova envergadura, estruturaram-se gradativamente às carreiras, assim como os procedimentos sujeitaram-se crescentemente à lógica racional-legal. Ao mesmo tempo, erigiu-se um novo aparelho de regulação e intervenção econômica; estruturou-se no Estado uma área social na qual passaram a ser gestadas políticas públicas de caráter nacional; finalmente, os orga- 
nismos coercitivos e repressivos estatais adquiriram substância qualitativamente nova (DRAIBE, 1986, p. 62).

Assim, baseado nessa nova forma de Estado, tem-se também uma nova postura deste em relação à sociedade civil, a qual a literatura consagra como intervencionismo (FONSECA, 1987). Desse modo, podemos listar entre as instituições criadas no pós-30: Ministério do Trabalho, Indústria e Comércio; em 1931, o Departamento Nacional do Trabalho; em 1934, o Conselho Federal do Comércio Exterior, o Plano Geral de Viação Nacional e a Comissão de Similares; e, em 1937, o Conselho Técnico de Economia e Finanças. Na área agrícola, cria-se, em 1931, o Conselho Nacional do Café (substituído, em 1933, pelo Departamento Nacional do Café) e o Instituto do Cacau da Bahia; em 1933, o Instituto do Açúcar e do Álcool; e, em 1934, o Instituto de Biologia Animal. Uma análise do caráter desses órgãos permite vislumbrar os traços principais do sentido pretendido pela ação governamental: a diversificação agrícola e o apoio ao crescimento industrial (FONSECA, 1987). Nesse contexto, a quantidade de instituições criadas, bem como sua variedade, coaduna-se com a tese de Fonseca (2003) sobre sua intencionalidade, ou seja, a existência consciente de um projeto de industrialização nacional que constrói seu sentido.

Soma-se a isso o Decreto ${ }^{\circ}$ 19.739, de 7 de março de 1931, que proibia a importação de máquinas por certas indústrias, e a criação da Carteira de Crédito Agrícola e Industrial do Banco do Brasil, em 1937, que deveria financiar a criação de novas indústrias. Esses dois fatores, segundo Fonseca (1987, p. 24), revelam que o governo procurou "[...] atender de perto as reivindicações dos empresários industriais [...]". Nesse contexto, ainda segundo o autor, há uma mudança de sentido na ação governamental após 1930, pois os diversos conselhos e órgãos criados caracterizam "[...] não apenas a burocratização e a racionalização na tomada de decisões, mas o sentido destas, já que às suas cúpulas foram trazidos empresários, muitas vezes os de maior liderança em seus setores, estabelecendo-se uma ponte direta entre Estado e burguesia industrial" (FONSECA, 1987, p. 25).

Já Ianni (1977), ao analisar este período, também enfatiza a mudança na relação entre o Estado e a economia. Nesse caso, redefine a aplicação das medidas econômicas para a formação do que chamou de "tecnocracia estatal" e a consequente hipertrofia do Poder Executivo. Avalia a ação do Poder Público na medida em que este pretende "[...] estabelecer novos padrões e valores, ou reafirmar os padrões e valores específicos das relações e instituições de tipo capitalista [...]" (IANNI, 1977, p. 22).

Do ponto de vista econômico, vários autores, ao enfatizarem as continuidades e descontinuidades na utilização do instrumental econômico (fiscal, cambial e monetário), veem no governo provisório um viés continuísta, enxergando como principais preocupações do novo governo os gastos públicos (VILLELA; SUZI- 

(1987):

\begin{abstract}
Embora o debate em torno das políticas monetária, cambial e fiscal tenha concentrado a maior parte dos esforços os economistas voltados ao estudo da economia brasileira na década de 1930, deve-se ter presente que o resgate do sentido da política econômica vai além delas. Assim, sem excluí-las, deve-se investigar outras questões de vulto, inclusive no plano institucional, como as diversas medidas adotadas no que tange ao reodernamento das diversas frações do capital [...] como do capital com relação ao trabalho [...]. Quanto a essas, desde logo evidenciam-se a extensão e o aprofundamento do intervencionismo [...] (FONSECA, 1987, p. 23).
\end{abstract}

Fica claro, nas avaliações realizadas, a profundidade da mudança realizada no pós-1930, estendendo-se desde a reproblematização da estrutura estatal até a possibilidade de industrialização nacional. Apresenta-se, assim, a conjuntura em que se constrói a Constituição de 1934.

\title{
4 A Constituição de 1934 e a Formação do Estado Desenvolvimentista: uma Interpretação
}

Ao longo da investigação, apresentaram-se três pontos basilares para o estudo do objeto: primeiro, insere-se no processo de generalização de relações capitalistas de produção, o qual desemboca, já na década de 1930, no movimento de industrialização nacional; segundo, aparece em um momento de crise do bloco de poder então hegemônico, baseado no discurso liberal; e terceiro, relaciona-se com a reorganização político-ideológica nacional, na qual se lançam as bases para a formação de um novo bloco de poder.

A Constituição de 1934 expressa, portanto, esse novo momento do país: superando o sujeito regional propagado pelo liberalismo, inicia-se a formação de um sujeito nacional, o qual, em nível jurídico-institucional, legitimará as principais tendências políticas do período, quais sejam, a centralização política e o intervencionismo estatal. A associação, nesse ponto, é nítida: o Estado nacional encarna a "vontade da nação". O sentido para essa reestruturação do Estado brasileiro se constrói aos poucos, na medida em que avança a reorganização político-ideológica do país e um novo discurso vai sendo criado.

A relativa autonomia do Estado, apontada por alguns autores, nesse contexto, resulta mais do que simples indefinição de classe: apresenta-se também como período de transição ideológica, com a qual uma nova realidade se configura. É essa trajetória que torna inteligível o caráter diverso da Carta Constitucional em análise. Lado a lado com elementos liberais, encontram-se outros tantos antiliberais. Nesse sentido, afirma-se: a Constituição de 1934 exprime os primeiros 
elementos jurídico-institucionais que embasarão a formação do Estado desenvolvimentista brasileiro. Mais do que isso, propicia um momento de condensação dos elementos constituintes do futuro discurso desenvolvimentista, na medida em que serve como ponto de associação entre elementos antiliberais, como os dois já citados. Desse modo, ela não é apenas a concretização de um discurso que se forma e que inicia a transformação da estrutura estatal; possibilita também a associação das tendências políticas antes expostas. Nesse contexto, vê-se o início da formação de um sujeito nacional calcado na ideia de "interesse nacional", a defesa do intervencionismo estatal, criando os primeiros instrumentos jurídicos para tanto, uma maior centralização política por parte do governo federal e um nascente tom nacionalista, como veremos adiante. Dentro desse arcabouço, a Carta Constitucional aqui analisada apresenta-se como materialização jurídica do Estado desenvolvimentista nascente, já que permite a condensação de elementos que, historicamente, formam o discurso que embasa as transformações.

\subsection{As Continuidades}

O enfoque aqui dado às transformações ocorridas no pós-1930 não representa a irrelevância das continuidades constatadas. Pelo contrário, sua investigação aparece como parte essencial de qualquer esforço de interpretação do período analisado. Nesse sentido, dentre as verificadas, duas revelam-se de profunda importância, quais sejam, a manutenção do sistema presidencialista e do federalismo. Os dois aspectos apresentam-se como pontos basilares da estrutura estatal durante a Primeira República e, apesar das críticas à exacerbada autonomia dos estados durante o pré-1930, não há grandes contestações sobre nenhum deles:

[...] o fundamental era manter o liberalismo, transformando-o através de novos expedientes políticos, em nome da própria democracia. É exatamente neste contexto que a defesa do presidencialismo, com a reforma do sistema eleitoral, é considerado medida essencial para a superação do mal criado pela "política dos governadores" [...] A questão do federalismo - sem dúvida alguma intrinsecamente relacionado com a anterior - não consegue polarização tão evidente. [...] Assim, paulistas, mineiros, gaúchos e baianos unem-se em torno dos princípios da descentralização do poder e, embora admitindo o estabelecimento de certos limites em nome da União, insistem que a manutenção do federalismo é elemento crucial à prática da liberal-democracia (GOMES, 1981, p. 60).

Fica evidente que, embora fossem questões centrais, tanto o federalismo quanto o presidencialismo não eram, no debate político da época, apresentados, em si, como problemas, apesar das críticas mais acirradas empreendidas por alguns grupos, como os tenentes. As contestações que surgiam apresentavam a necessidade de modificação de ambos os sistemas, porém nunca propunham aban- 
doná-los. Assim, o que aparece nos trechos citados são propostas de alterações no nível em que são aplicados dentro da organização estatal brasileira. O problema, nesse caso, desloca-se: o federalismo, em si, não comprometia a dinâmica política nacional; o que a deturpava era a distorção provocada pela "política dos governadores". É a partir daí que o "aumento dos vínculos federais" (BASTOS, 1987, p. 3) propostos pela Constituição ganha em sentido: tenta-se a centralização política dentro dos marcos construídos pela Constituição anterior, quais sejam, o presidencialismo e o federalismo. O caráter da Revolução de 1930, como auge de uma crise oligárquica (FONSECA, 1989), não representa uma ruptura com o liberalismo político esboçado nos contornos da Constituição de 1891, no entanto, inevitavelmente, propõe mudanças. Estas se constroem aos poucos, nos interstícios deixados pelo enfraquecimento das bases do antigo bloco de poder. Nesse contexto, as continuidades apresentadas evidenciam que 1930 representa a mudança, não a ruptura. Do mesmo modo, a Carta Constitucional produzida em 1934 não surge como contraponto às bases de sua antecessora, a de 1891, antes disso representa a formação de alguns elementos de contraste, sem, no entanto, propor uma transformação radical. Apesar disso, a própria modificação do federalismo em 1934, sem nunca contestar a autonomia dos estados, apenas seu grau, enfatiza uma reproblematização do tema. Lembrando Fonseca (1987, p. 31), "[...] mesmo as continuidades não deixam de descortinar a mudança das formas através das quais historicamente elas se reproduziram [...]”, tem-se que a própria problemática das continuidades enseja suas transformações, tendo em vista que supõe uma ressignificação de ambas. Tal questão será resolvida apenas em 1937, com o golpe do Estado Novo.

\subsection{As Descontinuidades}

Trata-se, agora, das descontinuidades apresentadas pela Constituição de 1934 em relação àquela construída em 1891. Como referido anteriormente, podem ser agrupadas em basicamente quatro grupos: início da formação de um sujeito nacional calcado na ideia de "interesse nacional"; criação de instrumentalização jurídica com o objetivo de possibilitar o intervencionismo estatal, principalmente nos assuntos econômicos; maior centralização política por parte do governo federal; e um nascente elemento nacionalista. Esses quatro elementos aparecem juntos pela primeira vez em uma Carta Constitucional, o que marca a relevância das modificações aqui apresentadas. Dentro desse arcabouço, entende-se a Constituição de 1934 como um dos primeiros marcos jurídicos que possibilitarão a formação do Estado desenvolvimentista brasileiro. Nesse contexto, a Carta permite a condensação de elementos que, historicamente, formam o discurso que embasa as transformações, qual seja, o desenvolvimentista. Desse modo, 
apresenta-se como parte da construção de uma forma institucional condizente com o paradigma em gestação em 1934, que redefinará as bases da ação estatal. A construção de ambos, nesse caso, faz parte do mesmo processo: a constituição de uma realidade que ressignifica o momento histórico vivido e forma o sentido das mudanças vistas então como necessárias. É sob esse prisma que se busca o sentido das descontinuidades verificadas.

\subsubsection{O Sujeito Nacional}

O início da formação de um sujeito ideológico nacional foi uma das principais modificações ocorridas no pós-1930. Ele aparece como superação do antigo sujeito regional apresentado pelo discurso liberal da Primeira República e surge na Constituição de 1934 como ideia de um "interesse nacional", visto como "interesse da nação". O próprio conceito de nação ganha em relevância, aparecendo inúmeras vezes na Carta Constitucional, principalmente quando representa "as necessidades da vida nacional" (BASTOS, 1987, p. 3). Além disso, tendo agora esse novo caráter, a defesa dos "interesses nacionais" representa o próprio sentido da Constituição, já que assenta as bases das relações jurídicas existentes no país. Verifica-se também, quando trata das competências da União, uma associação entre esta e a nação, o que não ocorria no pré-1930, dada a elevada autonomia dos estados. Nota-se, nesse caso, o início da vinculação entre nação e Estado, relação que será basilar no futuro discurso desenvolvimentista, já que o segundo apresenta-se como o representante dos interesses do primeiro.

\subsubsection{A Centralização Política}

Como referido na seção 4.1., a centralização política por parte do governo federal eleva-se mesmo considerando a manutenção do federalismo. Nesse sentido, tal fenômeno aparece como um reordenamento da estrutura estatal, visando um aumento dos vínculos federais (BASTOS, 1987). O federalismo, nesse caso, continuará vigorando, porém será sistematicamente enfraquecido pelo aumento das responsabilidades e competências da União. Nesse contexto, segundo Draibe (1986), o principal ponto no qual se verifica o aumento da concentração política relaciona-se à unificação da Justiça, definida pela Constituição em 1934. Nela o tema se refere ao fim da competência dos Estados de legislar sobre direito processual. Desse modo, segundo a autora, comparando-se a Carta de 1934 com a de 1891, tem-se que:

Os procedimentos da Justiça Comum foram objeto de regulação federal, modificando-se a sistemática da Constituição de 1891, pela qual cada Estado tinha seu Código de Processo. A Constituição de 1934 atribui à 
União a competência de legislar sobre direito processual (art. $\left.5^{\circ}, \mathrm{XIX}, \mathrm{a}\right)$ " [...] (DRAIBE, 1986, p. 64).

No entanto, ao lado dessa modificação aparece outra na estrutura do Judiciário, qual seja, a criação da Justiça Eleitoral, desde o início vinculada ao Judiciário federal. Draibe (1986) entende como elemento que visa a ampliação e regulamentação da cidadania social e política, tendo como consequência a construção de um Poder Judiciário unificado e centralizado:

Se o aparelho judiciário alcançou, através das novas medidas, um grau maior de unificação e homogeneização nacionais [...] inscreveu também na sua própria estruturação material a natureza dos conflitos que permearam a sociedade brasileira. Aí foram reguladas as relações entre o capital e o trabalho, enquanto se confirmaram objetivamente, na estruturação da Justiça Eleitoral, as pressões de setores médios e populares pela ampliação da cidadania política (DRAIBE, 1986, p. 65).

A reestruturação do aparelho estatal aparece não apenas como desmanche da rede de clientelismo montada durante a Primeira República, mas como condição para a ressignificação do próprio Estado, tendo em vista a nova função que assume no pós-1930, qual seja, a defesa dos interesses da nação. Modificar o Estado, nesse contexto, é condição necessária para modificar a nação, isto é, "desenvolvê-la”. Assim, compreendem-se também outras mudanças, já que 1934 surge como o momento em que se fixam os princípios da vitaliciedade, da inamovibilidade, irredutibilidade de vencimentos e a obrigatoriedade do concurso público para ingressar na magistratura. Essas medidas representam, inevitavelmente, parte do processo de racionalização do aparelho burocrático.

Além disso, outro ponto no qual houve uma centralização por parte do governo federal foi o estabelecimento da competência da União na elaboração, coordenação e fiscalização na construção e execução do então Plano Nacional de Educação. Tal tema possuía elevada importância para o governo constituído no pós-1930, tendo em vista ser uma das principais mudanças propostas pela então Aliança Liberal. Como afirma Fonseca (1987):

[...] a Plataforma [da Aliança] pregou a necessidade de substituir o ensino meramente teórico e preparador de elites [...] por outro, profissionalizante e preparador de mão-de-obra, no qual deveriam ser incluídas disciplinas sobre economia, contabilidade e administração. Esta era uma das mais caras reivindicações dos líderes empresariais, pois freqüentemente eram suas queixas de falta de mão-de-obra especializada, principalmente de "pessoal de escritório". (FONSECA, 1987, p. 22). 
Desse modo, compreende-se o caráter estratégico da área e o interesse do governo federal em centralizar suas operações. Nesse contexto, apesar de não se vincular a uma alteração na estrutura estatal, mantém o sentido das mudanças propostas.

\subsubsection{O Intervencionismo Estatal e o Nacionalismo}

A Constituição de 1934 construiu os primeiros instrumentos jurídicos que possibilitaram a intervenção estatal na sociedade civil. Tal postura firma-se ideologicamente mediante a formação do sujeito nacional anteriormente referido e a associação deste com o Estado, entendido agora como defensor dos interesses do primeiro. Dessa forma, o Estado adquire a legitimidade para empreender as mudanças que considera necessárias para o desenvolvimento da nação. É dentro desse contexto que se depreende o sentido da intervenção, que, na Carta Constitucional de 1934, aparece, principalmente, em mudanças referentes à possibilidade de monopólio estatal de alguma indústria, por motivo de interesse público e mediante pagamento de indenização. Tal aspecto vai ao encontro das mudanças ocorridas na década de 1930, quando se verifica a criação, por parte do governo federal, de órgãos e instituições, que visavam o aumento da diversificação agrícola e o crescimento industrial. O intervencionismo, agora expresso na Constituição de 1934, será durante toda a década elemento central na relação entre Estado e sociedade civil:

Conquanto a República Velha não estivesse diante de um Estado absenteísta - as políticas do café vinham de longa data -, a partir de 1930 o intervencionismo não só passou a abranger os diversos segmentos da economia e da sociedade e se expandiu verticalmente em cada setor, incorporando-se ao modus operandi do governo, mas transformou-se em ideologia (FONSECA, 1987, p. 24).

Já segundo Ianni (1977), 1934 marca a adoção, pela primeira vez, de uma postura explicitamente nacionalista e intervencionista, na medida em que define a necessidade de concessão federal para a exploração de qualquer mina ou jazida estabelecida em território nacional. Além disso, referindo-se ao elemento nacionalista, estabelece que as autorizações ficariam restritas a brasileiros ou a empresas estabelecidas no país, o que representa uma mudança de tom em relação ao capital estrangeiro, acostumado a concessões públicas tão frequentes durante a Primeira República. 


\section{Considerações Finais}

A importância histórica da Constituição de 1934 não é, necessariamente, fruto apenas da expressão de suas linhas. A relevância de certas mudanças não justifica análises superficiais. Assim como os homens, as leis apresentam-se como resultado de seu tempo. Nesse caso, a profundidade da Carta Constitucional de 1934 surge muito mais de sua significação, de seu sentido histórico, do que de sua concretude. Depreende-se dela uma nova conjuntura nacional, baseada no início do processo de industrialização e no desmanche do bloco de poder representado pela Primeira República. Desse modo, em seu texto há algo obsoleto, sobras de uma realidade que se debatia em suas próprias contradições, na tentativa de sobrevida. Porém, encontram-se também fatores novos, oriundos do berço de uma nova ideologia, apresentada como superação de antigas e atrasadas ideias. Raramente na história brasileira expressou-se de maneira tão cristalina o quão o valor de uma visão de mundo pode surgir não apenas da realidade que forma, mas também daquela que desconstrói. Nesse sentido, a Constituição de 1934 representa um momento raro para análise: em seu conteúdo, aparecem elementos do futuro discurso desenvolvimentista; no entanto, tendo 1934 como início da formação, e não da maturidade, representa, como aspecto primordial, o primeiro momento de debate entre um discurso liberal articulado e um nascente discurso antiliberal, mas que ainda não possui forma definida. Tem-se, assim, como matriz histórica do desenvolvimentismo, a crise do discurso liberal ocorrida a partir da década de 1920. A Constituição elaborada em 1934 expressa nitidamente esse novo momento histórico.

Afirma-se, assim, a relação entre a Carta Constitucional de 1934, o desenvolvimentismo e o Estado desenvolvimentista. A Constituição permite um momento de condensação das novas ideias, que, pela primeira vez, aparecem juntas em um texto constitucional. A originalidade desse movimento demonstra a profundidade da descontinuidade em relação ao pré-1930. Por mais que a tão badalada revolução não se apresentasse além do nível da retórica, na medida em que se constituiu muito mais como um golpe de Estado, é inegável o caráter de mudança. Esta existiu, foi efetiva e marca o início de um período, calcado na busca do desenvolvimento nacional. Dessa forma, o sentido do Estado desenvolvimentista emerge da realidade construída pelo discurso do qual resulta, qual seja, o desenvolvimentista. Portanto, a Constituição de 1934, apresentando o aspecto concreto de determinadas mudanças, delineia os contornos do início do processo de formação do Estado desenvolvimentista brasileiro. 


\section{Referências}

ALVARENGA JÚNIOR, M.; MATTOS, F.A.M. O conceito de socialização das perdas e seu papel na discussão da questão distributiva na obra Formação Econômica do Brasil, de Celso Furtado. Cadernos do Desenvolvimento, v. 17, p. 11-25, 2015.

AURELIANO, L. M. No limiar da industrialização. São Paulo: Brasiliense, 1981.

BACKES, A. L. Fundamentos da ordem republicana: repensando o pacto de Campos Sales. 2004. Tese (Doutorado em Ciência Política) - Programa de pós-graduação em Ciência Política, Universidade Federal do Rio Grande do Sul, Porto Alegre, 2004.

BASTOS, C. R. A constituição de 1934. BRASIL. A constituição de 1934. Brasília: Minter, 1987.

DEAN, W. A industrialização de São Paulo. São Paulo: Difel, 1971.

DRAIBE, S. M. Rumos e metamorfoses: estado e industrialização no Brasil: 1930/1960. São Paulo: Paz e Terra, 1986.

FAUSTO, B. Expansão do café e política cafeeira. In: FAUSTO, B. História geral da civilização brasileira: o Brasil republicano. São Paulo: Difel, 1975.

FERNANDES, F. Sociedade de classes e subdesenvolvimento. Rio de Janeiro: Zahar Editores, 1968.

FONSECA, P. C. D. A gênese regional da "Revolução de 30". Estudos Econômicos, v. 29, n. 1, p. 113-127, jan./mar. 1999.

FONSECA, P. C. D. Sobre a intencionalidade da política industrializante no Brasil na década de 1930. Revista de Economia Política, São Paulo, v. 89, n. 9, p. 133-148, jan./mar. 2003.

FONSECA, P. C. D. Gênese e precursores do desenvolvimentismo no Brasil. Pesquisa $\mathcal{E}$ Debate, v. 15, n. 2(26), p. 225-256, jul./dez. 2004.

FONSECA, P. C. D. Vargas: o capitalismo em construção. São Paulo: Brasiliense, 1989.

FONSECA, P. C. D. Estado e industrialização consciente: 1930-45. Questões de Economia Política, n.4, p. 20-32, 1987.

FRITSCH, W. Apogeu e crise na Primeira República: 1900-1930. In: ABREU, M. P. (org.). A ordem do progresso: cem anos de política econômica republicana 1889-1989. Rio de Janeiro: Campus, 1992.

FURTADO, C. Formação econômica do Brasil. São Paulo: Nacional, 1997.

GOMES, A. M. C. Confronto e compromisso no processo de constitucionalização (1930-35) In: FAUSTO, B. (org.). História geral da civilização brasileira. São Paulo: Difel, 1981.

IANNI, O. Estado e planejamento econômico no Brasil: 1930/70. Rio de Janeiro: Civilização Brasileira, 1977.

MELLO, J. M. Cardoso de. O capitalismo tardio. São Paulo: Brasiliense, 1982. 
PELAEZ, C. M. História da industrialização no Brasil. São Paulo: APEC, 1972.

SILVA, S. Expansão cafeeira e origens da indústria no Brasil. São Paulo: Alfa-Omega, 1976.

VILLELA, A.; SUZIGAN, V. Política do governo e crescimento da economia brasileira: 18891945. Rio de Janeiro: IPEA, 1973. (Séries Monografias nº 10)

Recebido em: 19/10/2017.

Aceito em: 20/01/2018.

(cc) BY 